\title{
MÉTODOS DE PESQUISA PARA A IDENTIFICAÇÃO DE FATORES DE EVASÃO E PERMANÊNCIA NA EDUCAÇÃO PROFISSIONAL
}

\author{
Research methods for the \\ identification of persistence and \\ dropout factors in vocational education
}

Paula Elizabeth Nogueira Sales*

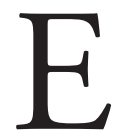

sta seçấo apresenta notas metodológicas de pesquisa ${ }^{1}$ sobre fatores de permanência e evasão escolar na educaçáo profissional de nível médio. A permanência e a evasão na formação técnica "é um fenômeno complexo, multifacetado e multicausal, atrelado a fatores pessoais, sociais e institucionais, que podem resultar na saída provisória do aluno da escola ou na sua saída definitiva do sistema de ensino" (DORE; SALES; CASTRO, 2014, p. 386). Diante da complexidade do problema da evasão, que envolve fatores individuais e institucionais, foram aplicados no referido estudo métodos mistos para coleta e análise de dados quantitativos e qualitativos.

* Programa de Pós-Graduação em Educação da Universidade Federal de Minas Gerais (UFMG), Brasil. 
Os fatores associados à evasão e à permanência foram levantados junto a 1.769 estudantes que abandonaram ou concluíram a formação técnica, entre 2006 e 2010, em 37 instituições da Rede Federal de Educação Profissional e Tecnológica de Minas Gerais. Para fins do levantamento, definiu-se como estudante evadido aquele que se matriculou e frequentou o curso técnico, deixando-o sem cumprir uma ou mais etapas necessárias à obtenção do diploma de técnico, a saber: disciplinas acadêmicas, disciplinas técnicas, estágio profissional e relatório de estágio. Já o estudante concluinte foi considerado aquele "que efetivamente concluiu os estudos regulares, estágios e outras atividades previstas no plano de curso e está apto a receber ou já recebeu o diploma” (MEC, 2008, p. 10).

Os 1.769 participantes da pesquisa se desdobram em 1.007 diplomados e 762 evadidos, que responderam a um questionário estruturado sobre suas trajetórias na formação técnica. Simultaneamente ao survey (levantamento), os fatores de evasão e conclusão foram explorados por meio de dez grupos focais, conduzidos com 32 diplomados e 31 evadidos de cursos técnicos.

O levantamento dos fatores associados à evasão e à permanência é relevante para produzir uma base de conhecimento do problema e subsidiar intervençôes que assegurem ao estudante as condiçóes necessárias para concluir sua formação escolar. Nessa perspectiva, a pesquisa analisou conjuntos de fatores individuais e institucionais que exercem influência nas performances acadêmicas e trajetórias estudantis.

Os fatores associados à evasão e à permanência escolar foram analisados a partir do modelo conceitual de performance estudantil (RUMBERGER; LIM, 2008), segundo o qual o abandono e a conclusão da escolaridade média são influenciados por dois tipos de fatores: a) individuais - associados às características individuais dos estudantes; e b) institucionais - associados aos três principais contextos que influenciam os estudantes: famílias; escolas; e comunidades. Esses fatores e suas respectivas categorias estão apresentados no Quadro 1. 


\section{QUADRO 1 - MODELO CONCEITUAL DE PERFORMANCE ESCOLAR NO ENSINO MÉDIO}

\begin{tabular}{|c|c|c|}
\hline Fatores & \multicolumn{2}{|c|}{ Categorias } \\
\hline \multirow{14}{*}{ Individuais } & \multirow{3}{*}{ Performance escolar } & Desempenho \\
\hline & & Persistência \\
\hline & & Escolaridade \\
\hline & \multirow{5}{*}{ Comportamentos } & Engajamento \\
\hline & & Aulas frequentadas \\
\hline & & Desvios \\
\hline & & Relaçóes com os colegas \\
\hline & & Empregos \\
\hline & \multirow{3}{*}{ Atitudes } & Objetivos \\
\hline & & Valores \\
\hline & & Autopercepção \\
\hline & \multirow{3}{*}{ Background } & Demografia \\
\hline & & Saúde \\
\hline & & Experiências passadas \\
\hline \multirow{9}{*}{ Institucionais } & \multirow{3}{*}{ Família } & Estrutura \\
\hline & & Recursos \\
\hline & & Práticas \\
\hline & \multirow{4}{*}{ Escola } & Composição \\
\hline & & Estrutura \\
\hline & & Recursos \\
\hline & & Práticas \\
\hline & \multirow{2}{*}{ Comunidade } & Recursos \\
\hline & & Composição \\
\hline
\end{tabular}

Fonte: Elaborado pela autora, com base em Rumberger e Lim (2008).

Os fatores individuais agrupam-se em quatro categorias: a) performance escolar - inclui o desempenho acadêmico, a persistência 
educacional e o nível de escolaridade alcançado; b) comportamentos engloba as condutas dos estudantes, como o engajamento com a vida escolar, as aulas frequentadas, os desvios (mau comportamento, uso de droga e gravidez), as relaçôes com os colegas e as situações de emprego; c) atitudes - inclui aspectos psicológicos, como as expectativas, os objetivos, os valores e a autopercepção; e d) background - engloba o perfil demográfico, a saúde e as experiências passadas, como a participação em pré-escola e atividades pós-escolares (RUMBERGER, 2011).

Embora as experiências, as atitudes, os comportamentos e o desempenho educacional exerçam influência sobre a conclusão ou o abandono escolar, tais fatores individuais também estão associados aos contextos institucionais dos quais os estudantes fazem parte.

Os fatores institucionais, que podem potencialmente influenciar os resultados educacionais dos estudantes, estáo reunidos em três categorias: a) família - abrange a estrutura (número e tipos de pessoas na família), os recursos familiares (financeiros e humanos) e as práticas da família (expectativas educacionais, suporte educativo e envolvimento escolar dos pais); b) escola - engloba a composição social dos estudantes na escola, a estrutura escolar (localização, tamanho e tipo de escola), os recursos físicos, humanos e financeiros da escola e as práticas escolares (administração, ensino e clima escolar); e c) comunidade - refere-se ao papel que as comunidades realizam no desenvolvimento dos jovens. As comunidades exercem influência por meio de: acesso a recursos, como creches, centros médicos e oportunidades de emprego; relaçóes parentais, que possibilitam o contato com familiares, amigos e vizinhos; e relaçóes sociais, que surgem da confiança mútua e dos valores compartilhados e que podem ajudar a supervisionar e monitorar as atividades dos jovens (RUMBERGER; LIM, 2008).

Ao integrar as abordagens quantitativa e qualitativa, o estudo desenvolvido possibilitou ampla triangulação dos dados. Tal procedimento abrangeu a aproximação da questão de pesquisa a partir de dados diversos, a fim de convergir, cruzar e validar os resultados obtidos (HEWSON, 2006). De um lado, o enfoque quantitativo possibilita a produção de estatísticas gerais sobre o problema, a partir de uma amostra significativa de estudantes, com potencial de generalização dos resultados; de outro, o enfoque qualitativo permite ao pesquisador detalhar 
questóes contextuais e individuais referentes aos motivos apontados pelos estudantes para concluir ou abandonar os estudos, a partir das histórias e experiências narradas.

Para Wolff, Knodel e Sittitrai (1993), quando pesquisas de survey e grupos focais apontam para as mesmas conclusôes, os resultados das análises independentes tendem à confirmação mútua. Se uma das análises identificou contradiçóes ou inconsistências sobre o objeto em estudo, a análise das demais fonte de dados pode ajudar a elaborar ou esclarecer os mecanismos subjacentes que produzem tais ocorrências. Nessas ocasióes, em que estudos de survey e grupos focais examinam diferentes dimensóes dos mesmos conceitos, os resultados podem levar a uma percepção mais profunda sobre a natureza desses conceitos, elevando a qualidade e a confiabilidade das análises desenvolvidas.

Orientado pelo procedimento metodológico aqui delineado, o estudo buscou desenvolver uma visão holística dos processos de conclusão e evasão da educação profissional de nível médio, necessária à formulação de estratégias e ações capazes de garantir a permanência do estudante na escola até a finalização do seu processo de formação para o trabalho.

\section{REFERÊNCIAS}

DORE, R.; SALES, P. E. N.; CASTRO, T. L. Evasão nos cursos técnicos de nível médio da Rede Federal de Educação Profissional de Minas Gerais. In: DORE, R. (Org.). Evasão na educação: estudos, políticas e propostas de enfrentamento. Brasília: IFB, 2014. p. 379-413.

HEWSON, C. Mixed methods research. In: JUPP, V. The Sage dictionary of social research methods. London: Sage, 2006. p. 179-181.

MEC. Pesquisa nacional de egressos dos cursos técnicos da Rede Federal de Educação Profissional e Tecnológica (2003-2007). Brasília: MEC, 2008.

RUMBERGER, R. Dropping out: Why students drop out of high school and what can be done about it. Cambridge: Harvard University Press, 2011.

RUMBERGER, R.; LIM, S. A. Why students drop out of school: A review of 25 years of research. Santa Barbara: University of California, 2008. 
WOLFF, B.; KNODEL, J.; SITTITRAI, W. Focus groups and surveys as complementary research methods. In: MORGAN, D. L. (Org.). Successful focus groups: Advancing the state of the art. Newbury Park: Sage, 1993. p. 118-136.

\section{NOTAS}

1. A pesquisa se intitula "Educaçáo Técnica de Nível Médio da Rede Federal de Educação Profissional e Tecnológica de Minas Gerais: organização dos IFs, políticas para o trabalho docente, permanência/evasão de estudantes e transição para o ensino superior e para o trabalho". É desenvolvida por um núcleo de estudos, no qual participam os Programas de Pós-Graduação em Educação da Universidade Federal de Minas Gerais, da Pontifícia Universidade Católica de Minas Gerais e do Centro Federal de Educação Tecnológica de Minas Gerais, no âmbito da Rede Ibero-Americana de Estudos sobre Educação Profissional e Evasão Escolar (Rimepes), cujo website é http://www.fae.ufmg. br/rimepes. Para o seu desenvolvimento, a investigaçáo tem o apoio da Coordenação de Aperfeiçoamento de Pessoal de Nível Superior (Capes), do Conselho Nacional de Desenvolvimento Científico e Tecnológico (CNPq), da Fundação de Amparo à Pesquisa do Estado de Minas Gerais (Fapemig), bem como das instituiçôes da Rede Federal de Educação Profissional de Minas Gerais.

Recebido em 10 de agosto de 2014.

Aprovado em 10 de novembro de 2014. 